\title{
Copulation and Egg Production of the Monogenean Heterobothrium okamotoi, a Gill Parasite of Cultured Tiger Puffer (Takifugu rubripes)
}

\author{
Kazuo Ogawa \\ Department of Aquatic Bioscience, Graduate School of Agricultural and Life Sciences, \\ The University of Tokyo, Yayoi 1-1-1, Bunkyo-ku, Tokyo 113, Japan
}

(Received August 28, 1997)

\begin{abstract}
The monogenean Heterobothrium okamotoi, parasitizing, in clusters, the branchial cavity wall of cultured tiger puffer Takifugu rubripes, were collected together with some host tissue, in which the posterior part of the parasite body was embedded, to make in vitro observations of copulation and egg production under the stereomicroscope. Some specimens copulated with other worms within the same cluster by attaching their male copulatory organ to the ventro-lateral or dorso-lateral body of their partners. Self-fertilization was also observed. Eggs were produced at about 2-min intervals. After egg assembly in the ootype, the egg was transferred to the uterus and large numbers of eggs accumulated there. Eggs were connected, at both ends, with previous and successive ones through a continuous filament, forming a long egg string. The length of the filament connecting the eggs corresponded with the length of the duct between the ootype and the uterus. Eggs were extracted from the uterus of freshly collected worms and counted. The highest number of eggs per worm exceeded 1,500. Based on the measurements of the egg and filament lengths and the number of eggs recorded, the longest egg string was calculated to be over $2.8 \mathrm{~m}$ long.
\end{abstract}

Key words: Monogenea, Heterobothrium okamotoi, copulation, egg production, tiger puffer

The genus Heterobothrium is a monogenean parasite of tetraodondid fish. In Japan, several species were collected and described from puffers of the genus Takifugu (see Ogawa, 1991). They were all gill parasites, and completed their parasitic lives only on the gills of the hosts, with the exception of $H$. okamotoi, which first infected the gills of tiger puffer Takifugu rubripes, but then migrated onto the branchial cavity wall for maturation (Ogawa and Inouye, 1997a). This particular mode of parasitism in $H$. okamotoi suggests that it has evolved quite differently from the other Heterobothrium species. It also indicates that there are some biological and ecological characteristics distinctive to this monogenean. This paper aims to describe some of these characteristics, especially those related to its reproduction.

\section{Materials and Methods}

\section{Observation of copulation and in vitro egg formation}

Adults of $H$. okamoto $i$ were often observed in isolated groups, each worm with its body partly embedded in the branchial cavity wall of the tiger puffer host. Sometimes more than 20 worms were found aggregated in a single cluster (Ogawa, unpublished data). One- year tiger puffer with groups of worms on the branchial cavity wall were sampled in Nagasaki Prefecture in February and March, 1995 and in Fukui Pref. in July, 1995. The clusters of worms were carefully removed together with the host tissue into which the posterior part of the parasiteís body was enclosed. They were placed in Petri dishes with seawater, and observed under a stereomicrocope with a minimum amount of lighting. Observations were made at room temperature within $2 \mathrm{~h}$ of dissection.

Diclidophorid monogeneans possess a ring of clawshaped spines at the terminal end of the male copulatory organ. Worms grasp a recipient with these spines and insert sperm directly into the recipient's body, as evidenced in vitro by Macdonald and Caley (1975) for Diclidophora merlangi.

\section{Measurement of mounted parasite specimens}

Randomly selected adult specimens ( $\mathrm{n}: 80$ ), collected in Nagasaki Pref. in 1985-95, fixed in AFA, stained with either alum carmine or Heidenhein's iron hematoxylin and mounted in Canada balsam were used. Body length and the length of the duct from the anterior end of the ootype to the posterior end of the uterus were measured 
with the aid of a curvimeter and a profile projector $(\mathrm{V}$ $16 \mathrm{E}$, Nikon, Japan) or a compact microscope equipped with a drawing tube (Nikon).

\section{Measurement of eggs from live specimens}

Live $H$. okamotoi adults were carefully removed from one-year tiger puffer cultured in Fukui Pref. in June, 1995. Parasites with eggs in the uterus were selected and placed in Petri dishes individually. Eggs were forcibly expelled from the uterus by gently pushing the midventral portion of the parasite body with forceps. The number of eggs was counted directly under a stereo-microscope, while they were being expelled from the body. The spindle-shaped eggs, connected to each other with a filament (Okamoto, 1963), were then fixed in 10\% formalin, and wet mount preparations made for egg measurement. The eggs and the filament were measured with the aid of a curvimeter.

\section{Results}

\section{Copulation}

A total of 11 probable cases of copulation were observed (Fig. 1). Most typically ( 7 cases), a worm copulated with another in the same cluster (Fig. 1b). One case of each of the following types of copulation was also observed: one worm performing self-fertilization (Fig. 1a), two worms copulating with each other (Fig. 1c), two worms copulating with a third (Fig. 1d), and one worm copulating with another which was performing self-fertilization (Fig. 1e). In any case, the male copulatory organ was firmly attached to the ventro-lateral or dorso-lateral body surface of the recipient, although no direct evidence was obtained that the donors did transfer their sperm into the recipients during the apparent copulatory period. The copulation lasted for up to $22 \mathrm{~min}$, despite frequent body movements by the copulating worms. Sometimes the male copulatory organ grasped the recipient's body so firmly and deeply that the donor and recipient could not separate from each other instantly.

\section{In vitro egg production}

After removal from the host, $H$. okamotoi continued to produce eggs whilst maintained in the Petri dishes. It was rather difficult to make a continuous observation of such parasites because of their frequent stretching, contracting and turning movements. However, three cases of consecutive egg production were observed under a stereo-microscope. There was some vacant space at the posterior end of the uterus. Thus, it was clearly determined when a newly-produced egg entered the uterus, and the time required for the production of each egg was accurately recorded (Table 1 ).

The time required for the production of an egg in the ootype varied, even in an individual parasite. However, the egg production process was very constant and cyclic. Figure 2 indicates the structure of the ovarian complex. It was assumed that, after copulation, sperm from donor parasites migrated to the vitelline reservoir and that fertilization took place before an ovum entered the ootype. On receiving a fertilized ovum together with a number of vitelline follicles, the ootyle contracted constantly, throughout what constituted the egg assembly process. This assembly process typically lasted $90-120 \mathrm{sec}$. During egg production, the enveloping Mehlis' gland secreted a substance into the ootype which coated successive eggs. As an egg advanced from the ootype to-
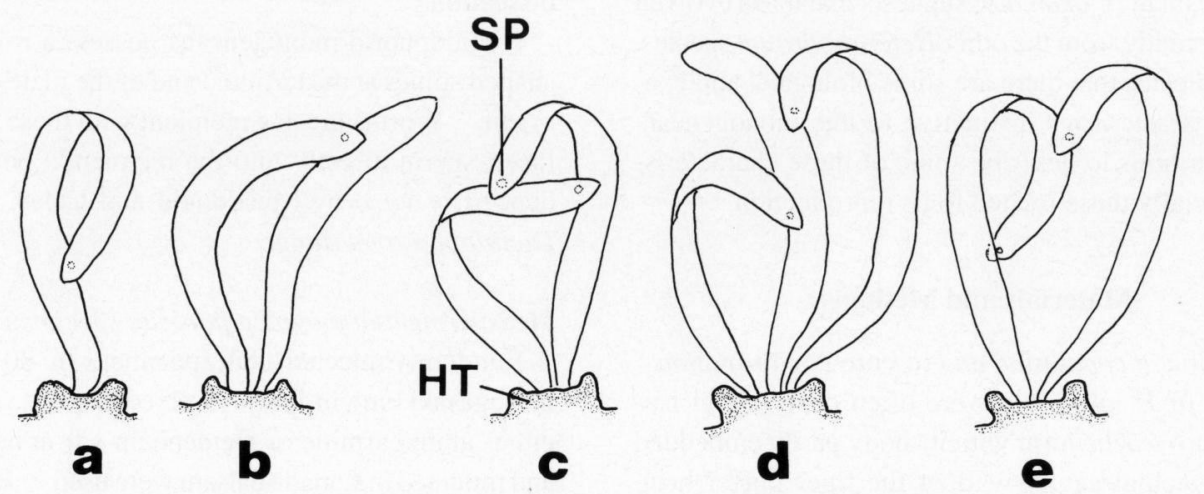

Fig. 1. A semi-diagrammatic figure illustrating various types of copulation in Heterobothrium okamotoi. HT, inflammatory host tissue, where a cluster of worms were embedded; SP, a ring of spines at the terminal end of male copulatory organ. 
Table 1. In vitro egg production of Heterobothrium okamotoi

\begin{tabular}{ccc}
\hline \hline $\begin{array}{c}\text { Specimen } \\
\text { no. }\end{array}$ & $\begin{array}{c}\text { Egg production cycle } \\
\text { (in sec) }\end{array}$ & $\begin{array}{c}\text { No. of consecutive egg } \\
\text { productions observed }\end{array}$ \\
\hline 1 & $94-140(108.8 \pm 13.1)^{*}$ & 20 \\
2 & $90-123(103.3 \pm 8.8)$ & 13 \\
3 & $119-158(140.2 \pm 15.2)$ & 6 \\
\hline
\end{tabular}

* Figures represent ranges, followed by averages $\pm S$. D. in parentheses.

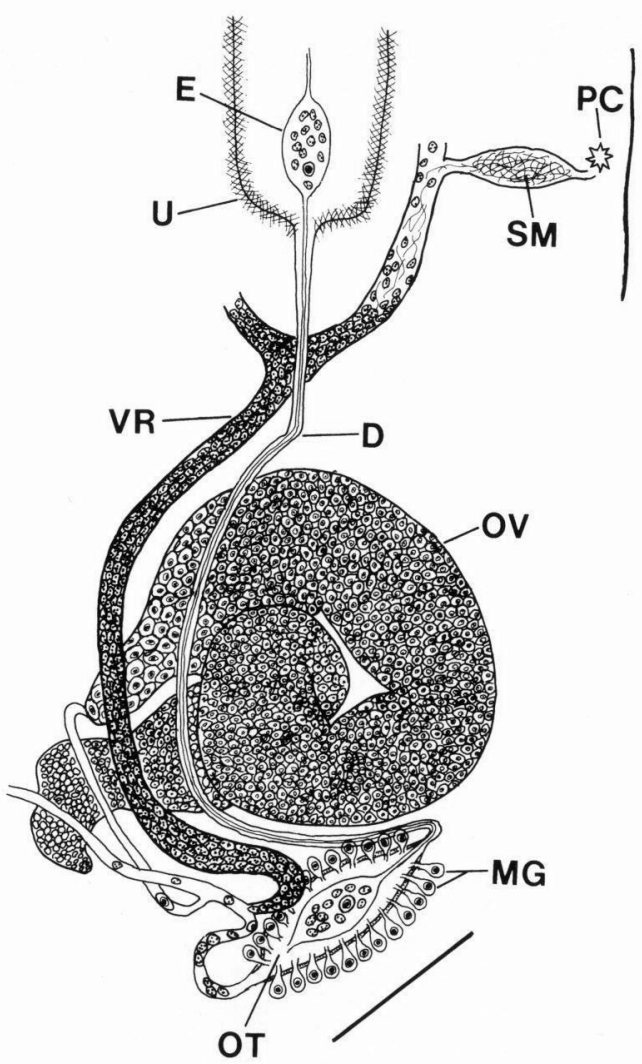

Fig. 2. A semi-diagrammatic figure of the ovarian complex of Heterobothrium okamotoi. D, duct between the ootype and the uterus; E, egg; MG, Mehlis' gland cells; OT, ootype; OV, ovary; PC, point of copulation; SM, sperm mass from a donor parasite; U, uterus; VR, vitelline reservoir. Scale: $0.2 \mathrm{~mm}$.

wards the uterus, possibly by the peristaltic contractions of the connecting duct, the secretion continued and was drawn into a filament behind the egg. The next egg produced in the ootype was similarly encased in the secretion and was thus linked by the filament to the previous egg. Egg formation within the ootype coincided with the entry of the previous egg into the uterus. Consequently, the length of the joining filament between eggs was approximately equivalent to the length of the duct connecting the ootype and the uterus. As production progressed, so the number of eggs in the uterus, connected together through the filament, increased. Each production cycle, from the egg assembly in the ootype to the egg's entry into the uterus, took about $2 \mathrm{~min}$. No pause was recorded in the above process.

\section{Measurement of mounted parasite specimens}

Parasites measured 9.0-23.1 mm in body length with the duct between the ootype and the uterus ranging from 1.05 to $2.44 \mathrm{~mm}$ long. From these measurements, a linear line, $Y=0.1204 X+0.2765$, was regressed, where $\mathrm{X}$ and $\mathrm{Y}$ represented the parasite body length and the duct length in $\mathrm{mm}$, respectively, with the correlation coefficient being $0.8351(P<0.001$; F-test $)$ (Fig. 3). This means that the larger the parasite, the longer the filament length between eggs.

\section{Measurement of eggs from live specimens}

Lengths of the eggs themselves and the intervening filament varied among parasite individuals, but they were quite constant within a single individual (Table 2). The number of eggs in the uterus was often found to be very different, but this may be due to the difference among individuals in time passed since their last egg-string deposition. From the measurements of egg lengths, filameant lengths and the number of eggs in the uterus, the length of the egg string was calculated (Table 2). This length varied markedly, depending on the number of eggs in the uterus, but it exceeded $1 \mathrm{~m}$ in most cases. The highest number of eggs in the uterus counted exceeded 1500, and the deduced egg string length was over $2.8 \mathrm{~m}$.

\section{Discussion}

Many types of copulation in $\mathrm{H}$. okamotoi were observed in vitro, and in 10 of 11 cases worms copulated with others within the same isolated groups. This suggests that copulation is not a rare event and that the aggregated parasitism on the branchial cavity wall of tiger puffer is favorable for the encounter of copulation partners. In wild populations of tiger puffer, when the level of Heterobothrium infection happens to be very low, it will be difficult for the parasite to find partners to copulate with. From the present observations, it is probable that they will self-fertilize in such a situation.

Copulation was not confirmed by the presence of the 


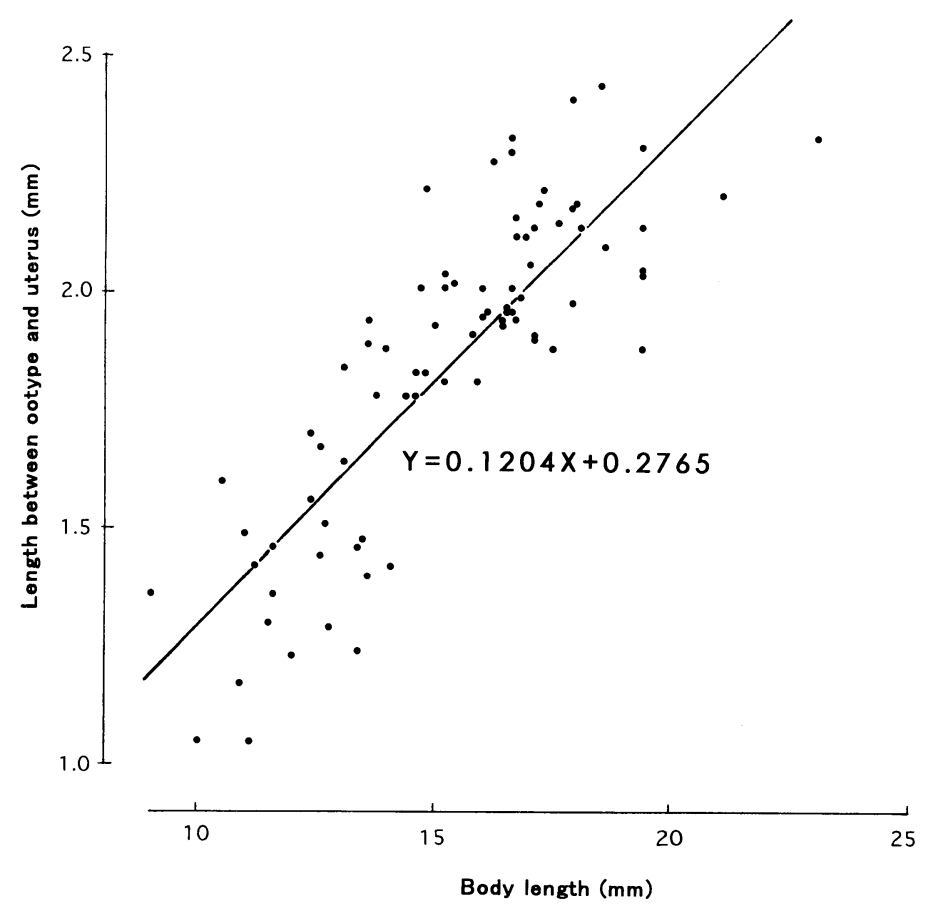

Fig. 3. Relationship between body length and the length of the duct between ootype and uterus in Heterobothrium okamotoi. Each dot represents an individual parasite.

Table 2. Egg count in the uterus and the measurement of the egg string length of Heterobothrium okamotoi

\begin{tabular}{ccccc}
\hline \hline $\begin{array}{c}\text { Specimen } \\
\text { no. }\end{array}$ & $\begin{array}{c}\text { Egg length } \\
\text { (in mm)*1 }\end{array}$ & $\begin{array}{c}\text { Filament length } \\
\text { (in mm)*1 }\end{array}$ & $\begin{array}{c}\text { No. of eggs } \\
\text { in uterus }\end{array}$ & $\begin{array}{c}\text { Total length of } \\
\text { egg string (in mm)*2 }\end{array}$ \\
\hline 1 & $0.22-0.24(0.229)$ & $0.94-1.29(1.164)$ & 1,309 & 1,820 \\
2 & $0.22-0.24(0.233)$ & $1.54-1.95(1.717)$ & 736 & 1,440 \\
3 & $0.26-0.28(0.269)$ & $1.46-1.71(1.577)$ & 793 & 1,460 \\
4 & $0.23-0.25(0.240)$ & $1.39-1.59(1.481)$ & 404 & 700 \\
5 & $0.23-0.25(0.232)$ & $1.45-1.66(1.555)$ & 1,583 & 2,830 \\
6 & $0.22-0.23(0.223)$ & $1.40-1.93(1.664)$ & 581 & 1,100 \\
7 & $0.21-0.22(0.214)$ & $1.36-1.57(1.474)$ & 461 & 780 \\
8 & $0.23-0.24(0.232)$ & $1.38-1.54(1.459)$ & 500 & 850 \\
9 & $0.24-0.25(0.247)$ & $1.36-1.47(1.410)$ & 910 & 1,510 \\
10 & $0.23-0.25(0.240)$ & $1.31-1.43(1.356)$ & 813 & 1,300 \\
Range: & $(0.214-0.269)$ & $(1.164-1.717)$ & $404-1,583$ & $700-2,830$ \\
\hline
\end{tabular}

*1 Figures represent ranges, followed by the averags in parentheses.

*2 Calculated figures based on egg and filament measurements and the number of eggs present.

donor's sperm in the recipient due to the recipient's well-. developed vitellaria obscuring the point of attachment of the donor's copulatory organ to its body, when observed in situ. In a previous paper, copulation was evidenced by the presence of sperm masses in the lateral region of the body of relatively young parasites in which vitellaria had not yet been fully developed (Ogawa and Inouye, 1997b). The sites of sperm masses observed in the previous study coincided with the attachment points of the copulatory organ in the present observation.

This is the second report of copulation in diclidophorid 
monogeneans, following that of Macdonald and Caley (1975) on Diclidophora merlangi. The mode of copulation was similar between $H$. okamoto $i$ and D. merlangi, but different in that the latter species always transferred sperm to the ventro-lateral body margin of the recepient, while $H$. okamotoi did so to both the ventro-lateral and dorso-lateral margins of the recipient.

Since the eggs counted in this study were pushed out of the parasite's body with forceps, the parasites may have actually had a potential to deposit more eggs than counted here. Even if the present calculation is an underestimate, it is suggested that H. okamotoi produces a very long string of eggs, the longest measured being over $2.8 \mathrm{~m}$. Although Okamoto (1963) observed that egg strings came out of the operculum of heavily infected fish, it still remains unclear whether eggs are deposited in the form of such a long string or as a mass in which eggs are entangled with each other. In any case, it is certain that a quite high percentage of deposited eggs become entangled with the net meshing which encloses cultured tiger puffer, resulting in an accumulation of eggs within the culture system.

Kearn et al. (1992) described that the egg appendage (= filament) of a capsalid monogenean Benedenia seriolae was about $0.5 \mathrm{~mm}$ long before egg deposition, but when released from the parasite it extended to 2-4 $\mathrm{mm}$ in length. However, in H. okamotoi, the length of the duct between the ootype and the uterus (Fig. 2) was not very different from the filament measurements of forcibly-deposited egg strings (Table 2). Besides, naturally-deposited eggs of $H$. okamotoi gave similar results to the present measurements (data not shown). Okamoto (1963) apparently measured naturally-deposited eggs of this species, and gave similar measurements for the eggs themselves $(0.2 \mathrm{~mm}$ long) and their connecting filaments (1.4 mm long). All these findings indicate that the egg filament of this species does not stretch after eggs are released to the seawater.
Concerning the potential egg production; $\mathrm{H}$. okamotoi can produce as many as 720 eggs in a day, based on the present observations of the egg production by the 3 adults (eggs produced at about 2-min intervals) and on the assumption that they produce eggs constantly throughout a $24 \mathrm{~h}$ period. The high potential of egg production and high probability of entanglement of deposited eggs with the culture net meshing suggest that frequent changes of net cages to remove entangled eggs will help reduce the infection level in the tiger puffer culture system.

\section{Acknowledgement}

The author expresses his gratitude to the staff of Nagasaki City Fisheries Center and Fukui Prefectural Fisheries Experimental Station for their help in collection of the parasite material.

\section{References}

Kearn, G. C., K. Ogawa and Y. Maeno (1992): Egg production, the oncomiracidium and larval development of Benedenia seriolae, a skin parasite of the yellowtail, Seriola quinqueradiata in Japan. Publ. Seto Mar. Biol. Lab., 35, 351-362.

Macdonald, S. and J. Caley (1975): Sexual reproduction in the monogenean Diclidophora merlangi: Tissue penetration by sperms. Z. Parasitenk., 45, 323-334.

Ogawa, K. (1991): Redescription of Heterobothrium tetrodonis (Monogenea: Dicridophoridae) and other related new species from puffers of the genus Takifugu (Teleostei: Tetraodontidae). Jpn. J. Parasitol., 40, 388-396.

Ogawa, K. and K. Inouye (1997a): Heterobothrium infection of cultured tiger puffer, Takifugu rubripes (Teleostei: Tetraodontidae) - a field study. Fish Pathol., 32, 15-20.

Ogawa, K. and K. Inouye (1997b): Heterobothrium infection of cultured tiger puffer, Takifugu rubripes - experimental infection. Fish Pathol., 32, 21-27.

Okamoto, T. (1963): On the problems of a monogenetic trematode infection of puffers from the Inland Sea of Japan. Suisanzoshoku, Special Issue No. 3, 17-29. (In Japanese.) 